\title{
STUDI SANITASI RUMAH KOS DAN PERILAKU HIDUP BERSIH SEHAT (PHBS) PADA PENGHUNI KOS DI KELURAHAN KARANGWANGKAL KECAMATAN PURWOKERTO UTARA KABUPATEN BANYUMAS TAHUN2016
}

\author{
Riza Bintang Pamungkas ${ }^{1)}$, Khomsatun ${ }^{2)}$ \\ Jurusan Kesehatan Lingkungan, Politeknik Kesehatan Kemenkes Semarang, \\ Jl. Raya Baturaden KM 12 Purwokerto, Indonesia
}

\begin{abstract}
Abstrak
Pembangunan kesehatan bertujuan untuk meningkatkan kesadaran kemauan dan kemampuan hidup bersih sehat bagi setiap orang agar menciptakan kesajahteraan yang optimal. Rumah sehat merupakan salah satu sarana untuk mencapai derajat kesehatan yang optimal, untuk memperoleh rumah yang sehat ditentukan oleh sanitasi perumahan. Tujuan penelitian Mengetahui keadaan sanitasi rumah kost dan Perilaku Hidup Bersih Sehat (PHBS) penghuni kost di Kelurahan Karangwangkal Kecamatan Purwokerto Utara Kabupaten Banyumas. Jenis penelitian ini merupakan penelitian observasional dengan analisis deskriptif untuk memperoleh gambaran tentang sanitasi rumah kos dan perilaku hidup bersih sehat (PHBS) penghuni kos, sampel yang diambil 26 rumah kos dari jenis 10 paviliun kos dan 16 induk kos, beserta penghuninya sebanyak 213 orang. Dan dibandingkan data hasil survey dengan standar yang sesuai peraturan kepmenkes No. 829/Menkes/SK/VII/1999,tentang Persyaratan Kesehatan Perumahan. Hasil wawancara,observasi dan pengukuran menggunakan kuesioner,checklist, dan alat ukur, hasil secara umum sanitasi rumah kos memenuhi syarat dengan rata-rata hasil penilaian 95,75\%, dan untuk penilaian Perilaku Hidup Bersih Sehat (PHBS) memenuhi syarat dengan prosentase 97,12\%. Pemilik kos melakukan pengecekan secara berkala pada bangunan kos,mengganti barang yang sudah tidak layak terpakai atau dapat membahayakan penghuni kos, dan memperbaiki bangunan kos yang sekiranya sudah lama termakan usia. Perlu adanya upaya untuk memperbaiki fasilitas-failitas kost/kamar yang kurang memenuhi syarat agar dapat menambah kenyamanan penghuni kos. Untuk penghuni kos mematuhi peraturan yang dibuat oleh pemilik kos atau rt/rw setempat dan menjaga hunian atau prabotan kos layaknya kepunyaan sendiri. dan menerapkan Perilaku Hidup Bersih Sehat (PHBS)
\end{abstract}

Kata Kunci : PHBS, sanitasi, rumah kos

\section{PENDAHULUAN}

Sanitasi rumah adalah usaha kesehatan masyarakat yang menitik beratkan pada pengawasan terhadap, struktur fisik dimana orang menggunakannya untuk tempat tinggal berlindung yang mempengaruhi derajat kesehatan manusia. Rumah juga merupakan salah satu bangunan tempat tinggal yang harus memenuhi kriteria kenyamanan keamanan dan kesehatan guna mendukung penghuninya agar dapat bekerja dengan produktif ( Budiman Chandra 2007).

Persyaratan kesehatan perumahan sesuai dengan Kepmenkes RI nomor: 829/MENKES/SK/VLL/1999, tentang persyaratan kesehatan tempat tinggal atau rumah yang meliputi persyaratan lingkungan perumahan seperti lokasi sarana dan prasarana lingkungan serta penghijauan, sedangkan persyaratan rumah tinggal meliputi bahan bangunan, komponen dan penataan ruangan pencahayaan, kualitas udara, ventilasi, penyediaan air bersih, pembuangan limbah dan kepadatan hunian.

Berdasarkan data yang di peroleh dari Kelurahan Karangwangkal Kecamatan Purwokerto Utara terdapat 124 rumah kost, diantaranya 78 jenis induk kos dan 46 jenis paviliun kos. Rata-rata penghuninya

1) Email : rizabintangpamungkas@ymail.com

2) Email : khomsatun@yahoo.co.id berasal dari luar kota dan daerah yang mempunyai perilaku serta budaya yang berbeda. Terdapat berbagai faktor yang mempengaruhi PHBS rumah kos, beberapa diantaranya adalah faktor pengetahuan, sikap dan perilaku pada penghuni kos. Perilaku penghuni yang kurang baik, membuat lingkungan kost terlihat menjadi kurang terawat atau tidak saniter. Hal ini terjadi karena kurangnya kesadaran para penghuni kost tentang pentingnya perilaku hidup bersih dan sehat (PHBS) yang harus dilakukan oleh setiap individu.

\section{METODE PENELITIAN}

Penelitian ini merupakan penelitian observasional dengan analisis deskriptif untuk memperoleh gambaran tentang sanitasi rumah kos dan perilaku hidup bersih sehat(PHBS) penghuni kos di Kelurahan Karangwangkal Kecamatan Purwokerto Utara Kabupaten Banyumas 2016.

Pelaksanaan inspeksi sanitasi rumah sehat meliputi aspek fisiologis, aspek psikologis, sanitasi dasar rumah, pencegahan terjadinya kecelakaan dilihat dari konstruksi bangunan. Dan penilaian terhadap perilaku hidup bersih sehat (PHBS) penghuni kos. Dengan subyek penelitian 
menggunakan metode purvosive sampling menurut suharsimi arikunto jika sampel diatas 100\% dapat diambil data menjadi 10\%-25\%,sehingga peneliti mengambil 20\% dari jumlah sampel rumah kos yang ada. Dan membandingkan hasil survey dengan standar yang sesuai dengan peraturan yang berlaku yaitu Kepmenkes No.829/Menkes/SK/VII/1999, tentang persyaratan kesehatan perumahan.

\section{III.HASIL DAN PEMBAHASAN}

Tabel 4.6 Hasil Inspeksi Sanitasi Rumah Kos

\begin{tabular}{|c|c|c|c|}
\hline \multirow[b]{2}{*}{ No } & \multirow[b]{2}{*}{ Variabel } & \multicolumn{2}{|c|}{ Hasil } \\
\hline & & $\begin{array}{l}\text { MS (Memenuhi } \\
\text { Syarat) }\end{array}$ & $\begin{array}{c}\text { TMS } \\
\text { (Tidak } \\
\text { Memenuhi } \\
\text { Syarat) } \\
\end{array}$ \\
\hline \multicolumn{4}{|c|}{ 1. Aspek fisiologis } \\
\hline & a.Suhu udara & $100 \%$ & $0 \%$ \\
\hline & b.Kelembaban & $100 \%$ & $0 \%$ \\
\hline & c.Pencahayaan & $100 \%$ & $0 \%$ \\
\hline & d.Ventilasi & $0 \%$ & $100 \%$ \\
\hline & e.Kepadatan hunian & $100 \%$ & $0 \%$ \\
\hline \multicolumn{4}{|c|}{ 2. Aspek Psikologis } \\
\hline & a. Privacy (rahasia) & $100 \%$ & $0 \%$ \\
\hline & $\begin{array}{l}\text { b. Kenyamanan } \\
\text { penghuni }\end{array}$ & $100 \%$ & $0 \%$ \\
\hline & $\begin{array}{l}\text { c. Penataan ruangan } \\
\text { sesuai fungsinya }\end{array}$ & $100 \%$ & $0 \%$ \\
\hline \multirow[t]{6}{*}{3.} & Sarana sanitasi dasar & & \\
\hline & $\begin{array}{l}\text { a.Penyediaan air } \\
\text { bersih }\end{array}$ & $100 \%$ & $0 \%$ \\
\hline & $\begin{array}{l}\text { b. Sarana } \\
\text { pembuangan air } \\
\text { limbah }\end{array}$ & $100 \%$ & $0 \%$ \\
\hline & $\begin{array}{l}\text { c. Jamban dan } \\
\text { septictank }\end{array}$ & $100 \%$ & $0 \%$ \\
\hline & d. Tempat sampah & $21 \%$ & $79 \%$ \\
\hline & & $100 \%$ & $0 \%$ \\
\hline
\end{tabular}

4. Pencegahan

kecelakaan dilihat

dari konstruksi

bangunan

$\begin{array}{lll}\text { a.Langit-langit } & 100 \% & 0 \% \\ \text { b.Dinding } & 100 \% & 0 \% \\ \text { c.Lantai } & 100 \% & 0 \% \\ \text { d.Jendela kamar } & 100 \% & 0 \% \\ \text { tidur } & & \end{array}$

Tabel 4.7 Hasil Inspeksi Perilaku Hidup Bersih Sehat (PHBS) Penghuni Kos.

\begin{tabular}{llcc}
\hline No & \multicolumn{1}{c}{ Variabel } & Ya & Tidak \\
\hline 1. & $\begin{array}{l}\text { Menggunakan air } \\
\text { bersih untuk kegiatan } \\
\text { sehari-hari }\end{array}$ & $100 \%$ & $0 \%$ \\
\hline 2. & $\begin{array}{l}\text { Mencuci tangan } \\
\text { dengan air bersih dan } \\
\text { sabun }\end{array}$ & $93 \%$ & $7 \%$ \\
\hline 3. & Menggunakan jamban \\
sehat & $100 \%$ & $0 \%$ \\
\hline
\end{tabular}

\begin{tabular}{|c|c|c|c|}
\hline & $\begin{array}{l}\text { Makan buah dan sayur } \\
\text { setiap hari }\end{array}$ & $96 \%$ & $4 \%$ \\
\hline 5. & $\begin{array}{l}\text { Melakukan aktivitas } \\
\text { fisik (olahraga) }\end{array}$ & $73 \%$ & $37 \%$ \\
\hline 6 . & $\begin{array}{l}\text { Merokok (untuk } \\
\text { responden laki-laki) } \\
\text { dan responden } \\
\text { perempuan }\end{array}$ & $\begin{array}{c}(45,68 \% \\
)-(3 \%)\end{array}$ & $\begin{array}{c}54,32 \\
\%)- \\
(97 \%)\end{array}$ \\
\hline 7. & $\begin{array}{l}\text { Mengganti sprei dan } \\
\text { sarung bantal } 2 \\
\text { minggu sekali }\end{array}$ & $99 \%$ & $1 \%$ \\
\hline 8. & Mandi 2 kali sehari & $100 \%$ & $0 \%$ \\
\hline 9. & $\begin{array}{l}\text { Mengganti baju kotor } \\
\text { dengan baju yang } \\
\text { bersih setiap hari }\end{array}$ & $100 \%$ & $0 \%$ \\
\hline $\begin{array}{l}10 \\
.\end{array}$ & $\begin{array}{l}\text { Menempatkan baju } \\
\text { kotor di keranjang } \\
\text { cucian (ember) }\end{array}$ & $99 \%$ & $1 \%$ \\
\hline
\end{tabular}

\section{IV.SIMPULAN DAN HASIL}

\section{Simpulan}

Pada 26 rumah,16 induk kos dan 10 paviliun kos di KelurahanKarangwangkal kec.purwokerto utara kab.banyumas,dapat di simpulkanbahwa :

a. Kondisi sanitasi rumah kos dari segi aspek fisiologis :

Suhu udara 100\% memenuhi syarat, kelembaban ruangan $100 \%$ memenuhi syarat, pencahayaan $100 \%$ memenuhi syarat, ventilasi alami tidak memenuhi syarat, dan kepadatan hunian 100\% memenuhi syarat.

b. Kondisisanitasirumahkosdarisegiaspekpsikologis "privacy":

100\% rumah kos dapat menyimpan rahasia/ benda pribadi dalam kamar (lemari), 100\% rumah kos nyaman untuk tempat tinggal dan 100\% rumah kos menata ruangan sesuai fungsinya.

c. Sarana sanitasi dasar :

Penyediaan air bersih $100 \%$ memenuhi syarat, sarana pembuangan air Iimbah 100\% memenuhi syarat, sarana pembuangan kotoran manusia (jamban) 100\% memenuhi syarat, sarana pembuangan sampah $21 \%$ memenuhi syarat sedangkan 79\% tidak memenuhi syarat, dan melakukan upaya pengendalian terhadap vector penyakit $100 \%$.

d. Pencegahan terjadinya kecelakaan dilihat dari konstruksi bangunan

$100 \%$ langit-langit rumah kos memenuhi syarat, $100 \%$ dinding rumah kos meemnuhi syarat, 100\% lantai rumah kos memenuhi syarat, dan $96 \%$ rumah kos mempunyai jendela.

e. Kondisi perilaku hidup bersih sehat penghuni kos (PHBS) :

$100 \%$ penghuni kos menggunakan air bersih untuk kegiatan sehari-hari,93\% penghuni kos menggunakan air bersih dan sabun untuk mencuci tangan sedangkan 7\%tidak menggunakan sabun saat mencuci tangan, $100 \%$ penghuni kos 
menggunakan jamban sehat, 96\% penghuni memakan buah dan sayur setiap hari sedangkan 4\% tidak makan buah dan sayur setiap hari, 73\% penghuni kos melakukan olahraga sedangkan 27\% tidak melakukan olahraga, dan 100 penghuni kos laki-laki 45,68\% merokok, 54,32\% penghuni kos tidak merokok, dan dari 113 penghuni kos perempuan ,97\% tidak merokok dan 3\% merokok. 99\% penghuni kos mengganti sprei 2 minggu sekali sedangkan 3\% penghuni kos tidak, mengganti sprei secara rutin, $100 \%$ penghuni kos mandi dua kali sehari, $100 \%$ penghuni kos mengganti baju kotor dengan baju yang bersih setiap hari, 99\% penghuni kos menempatkan baju kotor di keranjang cucian (ember) sedangkan 1\% penghuni kos menempatkan baju kotor disembarang tempat.

\section{Saran}

a. Bagi masyarakat

1. Pemilik kos

Melakukan pengecekan secara berkala pada bangunan kos,mengganti barang yang sudah tidak layak terpakai atau dapat membahayakan penghuni kos, dan memperbaiki bangunan kos yang sekiranya sudah lama termakan usia. Perlu adanya upaya untuk memperbaiki fasilitas-failitas kost/kamar yang kurang memenuhi syarat agar dapat menambah kenyamanan penghuni kos.

2. Penghuni kos

Mematuhi peraturan yang dibuat oleh kelurahan atau rt/rw setempat dan menjaga hunian atau prabotan kos layaknya kepunyaan sendiri. Untuk menciptakan kesehatan pada masing-masing penghuni kos hendaknya, menerapkan Perilaku Hidup Bersih Sehat (PHBS) seperti, jangan membungan sampah sembaragan,jangan merokok,cucilah tangan dengan sabun sebelum makan, mandi 2 kali sehari, dan membiasakan memakan buah dan sayur setiap hari, menjadikan olahraga menjadi kebutuhan hidup agar sehat jasmani, mengganti sprei secara rutin, dan menempatkan pakian kotor pada keranjang ember.

b. Bagi Pemerintah

Khususnya untuk Dinas Kesehatan minimal 1 tahun sekali untuk melakukan inspeksi sanitasi rumah dan memeberikan penyuluhan kepada penghuni kos yang ada di Kelurahan Karangwangkal tentang pentingnya Perilaku Hidup Bersih Sehat (PHBS) dan menginspeksi rumah-rumah kos agar selalu memenuhi Setandar kesehatan.

\section{DAFTAR PUSTAKA}

Anwar, et al, 1998, Pedoman Studi Makanan dan Minuman, Jakarta : Pusat Pendidikan Tenaga
Kerja Kesehatan Depkes Amalia Imazka, Studi Sanitasi Rumah Tipe 36 Pada Perumahan Griya Satria Bantarsoka Kecamatan Purwokerto Barat Kabupaten Banyumas Tahun 2012, Purwokerto : Kementrian Kesehatan Republik Indonesia Politeknik Kesehatan Kementkes Semarang Jurusan Kesehatan Lingkungan Purwokerto

Arc. Aria, 2010 at Membangun Rumah Yang SehatSirkulasi Udara Dalam Ruangan Serta Pengaturan Ruang Berdasarkan Sinar Matahari. Architectaria.com diakses pada tanggal 21 juni 2015

Budiman Chandra, 2007, Pengantar Kesehatan Lingkungan, Jakarta EGC Penerbit Buku Kedokteran

H.J Mukono, 2006, Prinsip Dasar Kesehatan Lingkungan Edisi Ke Dua, Surabaya : Airlangga University Press

Indonesia, 1999, Kementrian Kesehatan Republik Indonesia, Kepmenkes RI No:829/Menkes/SK/VII/1999 Tentang Persyaratan Kesehatan Perumahan, Jakarta: Kementrian Kesehatan RI

Indonesia, 2002 Pedoman Teknis Penilaian Rumah Sehat, Jakarta : Departeman Kesehatan RI Direktorat Jendral PPM \& PL

Indonesia, 2004, Kementrian Kesehatan Republik Indonesia, Kepmenkes RI No 1193/Menkes/SK/X/2004 Tentang Perilaku Hidup Bersih dan Sehat, Jakarta : Kementrian Kesehatan RI

Mustikasari, Studi Sanitasi Rumah Type 29 Ditinjau dari Aspek Pencegahan Penyakit Di Gnya Satria Mandalatama Kecamatan Karanglewas Kabupaten BanyumasTahun 2012, Purwokerto : Kementrian Kesehatan Republik Indonesia Politeknik Kesehatan Kementkes Semarang Jurusan Kesehatan Lingkungan Purwokerto

Nur A, dick, 2005, SanitasiRumah, Surabaya : Jumal Kesehatan LingkunganVol 1 no 2

Suparlan, 2012, Pengantar Pengawasan HygieneSanitasi Tempat-Tempat Umum Wisata\& Usaha-Usaha Untuk Umum, Surabaya : Dua tujuh

Suyono 2012, Ilmu Kesehatan Masyarakat Dalam Kontes Kesehatan Lingkungan, Jakarta : EGC Penerbit Buku Kedokteran

Soekidjo Notoatmodjo, 2007, Promosi Kesehatan \& Ilmu Perilaku, Jakarta : Rineka Cipta 
S. Nasution, 2000, Metode Research (PenelitianIlmiah), Jakarta : Bumiaksara

Tri Cahyono, 2014, Pedoman Penulisan Proposal Penelitian Dan Karya Tulis Ilmiah/Skripsi (Edisi Revisi Ketiga), Purwokerto: Politeknik Kesehatan Kemenkes Semarang Jurusan Kesehatan Lingkungan.

Undang-Undang Republik indonesia No 4 Tahun 1992 Tentang Perumahan dan Permukiman

www.promkes.depkes.co.iddiaksestanggal

Februari 2016dan15 Juni 2016
www.dinasperumahan.Qo.iddiaksesrabu 6'Februari 2015

www.hukumonline.comdiaksesselasa 12 februari 2015

www.kamusbesarbahasaindonesia.comdiaksesjumat 15 Februari 2016

www.promkes.depkes.co.id diakses tanggal 12 Februari 2016 dan15 Juni 2016 